\section{In Reply: Radiofrequency Ablation (RFA) of Pulmonary Metastases: Technical Success vs. Actual Benefit}

\section{TO THE EDITORS:}

Thank you for your letter. I would like to address your questions in regard to the rationale in treating these socalled "palliative" patients with RFA. We have labeled three patients as "palliative" because of either evidence of coexisting bony metastases or the extent of pulmonary disease as in the patient with 17 pulmonary metastases. I would agree that the treatment of only some of the metastases would not provide any survival benefit. However, RFA was not the only treatment modality in this group of patients, but was used as an adjunct to their treatment. In addition to their RFAs, these patients had received a combination of systemic therapies in the form of interferon, 5-FU, and interleukin-2. They also had further resections of metastases in the brain or lung and radiotherapy to bony disease. Despite the combination of these various forms of treatments, we felt that we were unlikely to provide a cure for these patients, but instead we hoped to provide some survival benefit with a multimodality approach to these young patients. Thus, RFA under these circumstances could not be considered potentially curative.

As to the question regarding whether metastasectomy does actually make any difference in survival benefit, I would agree that a 5-year survival period in patients with favorable tumor biology may not prove that their treatment has prolonged their life. Certainly, we know that renal cell carcinoma does have a relatively variable natural history. In the article written by Aberg et al. in 1980 which you have quoted (based on their study of the available literature at the time which were not specific to RCC), they had postulated that patients fulfilling the criteria for pulmonary resections for metastases constitute a selected group with a favorable natural history and that a 10 -year survival period would provide a better evaluation of benefit. ${ }^{1}$
There are two points to be made about these comments. Firstly, Pfannschmidt et al. and Piltz et al. were able to conclude from their studies that complete pulmonary resections conferred significant improvement in survival rates over patients with incomplete resections. ${ }^{2,3}$ In both of these studies, only patients with no evidence of locoregional recurrence of their primary $\mathrm{RCC}$ and no extrapulmonary metastases were included. Secondly, our study has 2 patients who have undergone RFAs and are still alive without any evidence of residual disease after 63 and 85 months. One patient had a liver resection and adrenalectomy that occurred 2 years after the nephrectomy and then underwent a cholecystectomy 6 weeks after his RFA. The other patient had undergone multiple pulmonary resections and cerebral metastasectomy between 1 and 2 years post-nephrectomy. These were all proven to be RCC in origin. Given the metastatic behavior of their tumors, these two patients cannot be described as having favorable tumor biology despite one patient having a histologically grade 2 tumor and the other having a grade $3-4$. From our experience, we feel that patients may still be potentially cured or at least benefit from long-term survival if their metastastic disease (pulmonary and extrapulmonary) could be treated by a combination of vigorous metastasectomy and RFAs.

\section{Andrew Huo, MBChB}

Department of Surgery, St George Hospital, Sydney, NSW, Australia

e-mail: andy.huo@hotmail.com

Published Online: 20 January 2010

(C) Society of Surgical Oncology 2010

\section{REFERENCES}

1. Aberg T, Malmberg KA, Nilsson B, Nou E. The effect of metastasectomy: fact or fiction? Ann Thorac Surg. 1980;4:378-84.

2. Pfannschmidt J, Hoffmann H, Muley T, Krysa S, Trainer C, Dienemann H. Prognostic factors for survival after pulmonary resection of metastatic renal cell carcinoma. Ann Thorac Surg. 2002;74:1653-7.

3. Piltz S, Meimarakis G, Wichmann MW, Hatz R, Schildberg FW, Fuerst H. Long-term results after pulmonary resection of renal cell carcinoma metastases. Ann Thorac Surg. 2002;73:1082-7. 